\title{
Catastrophic flood in the Odra river basin : experience gained during and after the flood
}

\author{
Inondations catastrophiques dans le bassin de l'Oder : \\ l'expérience gagnée pendant et après l'inondation
}

\author{
by Janusz Zelazinski \\ Institute of Meteorology and Water Management
}

Pendant les inondations catastrophiques du bassin de l'Oder en juillet 1997, la décharge maximum observée dans la partie amont du bassin était environ deux fois plus importante que celle observée pendant les 150 dernières années. Le montant des dégâts s'élevait à : 470 millions d'ECU en république tchèque, 2,31 milliards d'ECU en Pologne et 325 millions en Allemagne. En Pologne, on déplore la mort de 54 personnes. Les pluies ont été particulièrement abondantes, mais l'absence d'une stratégie adaptée a été la cause de tant de dégâts. L'article mentionne la liste des fautes particulières ainsi que les actions indispensables pour minimiser les dommages. Les cinq phénomènes suivants semblent particulièrement importants : l'absence d'informations, une gestion de la plaine inadaptée, la sous-estimation des incertitudes, le cercle vicieux du contrôle de l'inondation et le piège de prendre ses désirs pour des réalités. Les solutions pour éliminer ces phénomènes par des changements de loi, des travaux de recherche, l'éducation, les nouvelles technologies et la négociation publique, sont évoquées.

\section{I INTRODUCTION}

The catastrophe in the Odra River basin in July 1997 was related by media and described in many papers (for instance in a report prepared by "Miedzynarodowa Komisja Ochrony Odry", [1]). However experience belongs partially to category of conclusions and usually contains subjective interpretations of a given fact. A following example is illustrating above statement. During the flood most of the existing embankments were destroyed - it was a fact. Experience formulated by environmentalist runs as follows: "embankments of the river valley is not a proper method of flood protection", but experience formulated by hydraulic engineers is rather: "technical parameters of existing levees should be upgraded and this is a proper way of flood control". Experiences described in this paper represent my personal interpretation and cannot be considered as universal experiences commonly accepted in Poland. Formulation of general experience resulting from a flood event and satisfying for all groups of interest seems to be impossible because of many conflicts of interests and deep uncertainty involved in the flood mitigation problems. Only a compromise, often very difficult, seems to be an adequate solution and it is in my opinion the most important experience. I will try to formulate in this paper a way to achieve a compromise, but we have to keep in mind that compromised solution never satisfies everybody.

\section{II — FACTS}

The sources of the Odra River are located in the Oderske Vrchy mountains in the northern part of Czech Republic, $632 \mathrm{~m}$ above sea level. Mouth of the river at the Baltic See creates a big complex estuary (crossed by a Polish - German border). First $120 \mathrm{~km}$ of the Odra River is crossing Czech Republic, next $520 \mathrm{~km}$ is crossing Poland and the last $220 \mathrm{~km}$ of the river creates Polish - German border. Total watershed area is $118861 \mathrm{~km}^{2}$ (89\% of the area belongs to Poland, $6 \%$ to Czech Republic and 5\% to Germany). The Odra River is mostly a typical low-land river (excluding the first $47 \mathrm{~km}$ ). However, the largest upper Odra River tributaries (Opava, Ostravice, Olza, Nysa Klodzka, Bystrzyca, Kaczawa, Bobr) are the typical mountain rivers where the heavy rainfalls cause a dangerous flood (espacially in summer time). Many historical cities and industrial centers are located in the river valley and exposed to flood damages: Ostrava, Raciborz, Kedzierzyn/Kozle, Opole, Brzeg, Wrpclaw, Nowa Sol, Eisenhuttenstadt, Frankfurt, Schwedt, Szczecin.

From 4 to 9 th July and again from 17 to 21 st July 1997 an extraordinary heavy rain in upper parts of watershed caused two flood waves. During the first rain event the total amount of precipitation recorded at mountains reached $586 \mathrm{~mm}$ (234 $\mathrm{mm}$ during 24 hours). During the second event the 
amount of precipitation reached $167 \mathrm{~mm}$. The first flood wave was greater than the second. Long time of high water level caused increased flood damages.

We have about 150 years of systematic hydro-meteorological records for the Odra River basin. But observations only from the last 60 years seem to be homogeneous. In the upper part of a basin maximum observed discharge in 1997 (Raciborz $3260 \mathrm{~m}^{3} / \mathrm{s}$, Opole $3500 \mathrm{~m}^{3} / \mathrm{s}$ ) was about two times greater than observed earlier.

Estimated monetary value of a flood damages were as follows: 470 millions ECU in Czech Republic, 2.31 milliards ECU in Poland and 325 millions ECU in Germany. In Poland 54 persons died. Flooded area was about 500000 ha, number of evacuated persons was 106,000 . There are destroyed: $467 \mathrm{~km}$ of river embankments $(25 \mathrm{~km}$ totally and $442 \mathrm{~km}$ partially), 12 hydraulic structures, 47,000 buildings, 2000 kilometers of roads and railroads, 1700 bridges, 300 historical monuments, 937 school buildings, 100 water intakes and many others, 70 waste water treatment plants and 7 waste deposits were flooded.

\section{III — EXPERIENCES}

\section{- 3.1 List of the particular faults}

(1). Lack of proper quantitative precipitation forecasts $(\mathrm{QPF})$. During the flood QPF prepared in a few Polish and European meteorological centers (using mezoscale meteorological computer models) were accessible. All of them have a form of maps showing spatial distribution of the future precipitation. Obviously each model gives more or less different forecasts. Using above maps and subjective judgement meteorological forecaster on duty formulates QPF for hydrology. Here is an example of QPF given at 4th July 1997 at noon: "between 8 p.m. on 5th July and 8 p.m. on 6th July in upper Odra basin, the daily amount of precipitation can achieve in some places $45-75 \mathrm{~mm}$ ". In fact, during above listed 24 hours, the amount of precipitation recorded in upper Odra basin was higher than $75 \mathrm{~mm}$ only in three places. Therefore it was a very good QPF (leading time of 56 hours and relatively small errors). During the next few days QPF was a little bit worse because heavy rain was unexpectedly persistent. Above QPF can be very useful as a signal of possibility of flood. But in my opinion even the first QPF does not satisfy hydrological needs - time step is too long and space resolutions is to rough. Hydrologists need (as an input for hydrologic model) QPF formulated as an average amount of precipitation for each sub-catchment area of about $1000 \mathrm{~km}^{2}$ (over all catchment area covered by rain), and for each 1-3 hours time step to prepare useful hydrological forecast in mountains area. Leading time of QPF should be in range of $24-72$ hours. During my $40-$ years professional experience there is no progress concerning the possibility of satisfaction described above needs, in spite of implementation of super computers, satellite images, meteorological radars and other high-technology devices. Lack of QPF generates large errors in hydrological forecasts and then causes many inadequate or belated decisions, which cause increased flood damages.

(2). Collapse of information system. Up to now in Poland there is no automatic (telemetric) reliable system for collection and transmission of hydro-meteorological information. Existing system is based on a man-made observation and phone; radio and fax data transmission was broken by flood. Lack of information was an important reason of increased flood losses.

(3). Inability of managers to make proper decisions under deep uncertainty. During and especially after the flood we could observe the phenomena of "transfer of responsibility". Managers want a certain information about the future - perfect forecasts (their expectations are absolutely unrealistic). Typical dialog between manager and forecaster looks as follow. Forecaster says: "during the next $12-36$ hours we expect maximum water stage between 700 and $800 \mathrm{~cm}$ ". Manager says: "well, but when and how many centimeters will be in fact? Forecaster: "I do not know exactly". Manager: "You must tell me that, it is your duty!" Forecaster: "expected values are: time to peak 24 hours and maximum water stage $750 \mathrm{~cm}$. Managers handle the last statement as real, what leads mostly to bad decision. Of course from manager's point of view hydrologist - forecaster bears the responsibility. Obviously hydrologist - forecaster affirms that his mistake was caused by a wrong meteorological forecast. Because perfect forecast seems to be impossible only managers should be fully responsible for the results of their decision. In the next paragraphs I will try to show how uncertain information should be used in decision making process.

(4) Improper flood plain management. The last catastrophic flood in the Odra River basin before July 1997 was in 1903. After the 1903 flood many flood control reservoirs, embankments, polders etc. were constructed. These works and a long time without the major flood created illusion of full safety. It resulted in rapid growth of settlement over the flood plain, even in the polders. It was a fundamental reason of major damages in 1997.

(5). Inadequacy of flood frequency analysis as a standard methodology for designing a flood control measures. Standard flood frequency analysis (FFA) led to estimate the return period of the 1997 flood in a range of 10,000 years. It seems to be nonsense. In fact we know about the 1997 flood only that it was the greatest flood over the last $100-150$ years and nothing more. Short explanation of above statement runs as follows. FFA is based on a following strong but false or impossible to verify assumptions:

- The assumption of stability of the river flow process. False because climate has changed many times in Poland from arctic to tropic.

- The assumption of ergodicity of the river flow process. Impossible to verify, because we know only one world with one history and hypothesis of ergodicity (averaging over the realization gives the same results as averaging over the time) can not be verified.

- The assumption of a given type of probability of maximum flow distribution. False because there is a set of different distributions not contradictory with our sample distribution, but leading to great differences in estimation of the rare event.

- The assumption that a set of annual maximal river flows is homogeneous. False because we have many examples over the world that extraordinary events and common events are caused by other reasons. For instance, from time to time a very big flood waves in upper part of Loire River basin are caused by heavy rains coming from Mediterranean See. But the majority of flood waves in Loire River basin are caused 
by precipitation coming from Atlantic Ocean - then, a set of annual maximum outflow of Loire River is not homogeneous, because they are caused by different reasons.

The above four assumptions are indispensable if we want to use statistics for evaluation of the "designed flood" to design some hydraulic structure. But we cannot ignore uncertainty following from these assumptions. Fundamental deficiency of FFA is that it does not take into consideration the maximum entropy principle [2]. I tried to evaluate a random error of FFA estimation taking into account the maximum entropy principle (i.e. taking into account errors resulted from four discussed assumptions). These numerical experiments showed very big errors and gave reasons to conclusion that our knowledge about magnitude of rare floods does not increase by application of FFA comparing to knowledge drawn from simple analysis of observational sample.

(6) Lack of a proper organization of an operational flood control. In Poland operational flood control depends on local administration duties. First of all, floods (and generally all of the water concerned activity) should be managed within the basin borders not in an administrative one. Moreover local administrations staff has inadequate knowledge necessary for efficient actions. Existing obscure partition of authorization between local and water administrations cause many improper and belated decisions and inefficient operation of the flood control reservoirs (case Nysa Klodzka Cascade in 1997).

(7) Ignorance of proper behavior during flood period among the population exposed to flood risks. Lack of the proper information and education cause irrational behavior, i.e. refusal of evacuation.

(8) Improper insurance policy. Insurance rates are the same in a safe as well as in exposed to flood risk areas. In some cases flood damages can be a good business for users of flooded area. It can cause development of flood sensitive activities over a flood plane.

(9) Bad technical conditions of existing levees and too small capacity of the flood control reservoirs. Two reasons implied above facts: permanent shortage of money and very long period without flood.

\subsection{General conclusion - inadequacy of existing strategy of flood control}

Before the 1997 flood event some relatively developed system of flood control in Poland existed (legal base, information systems, organization, embankments, reservoirs and another flood mitigation measures). Each Polish tax - payer spend some money for creation and operation of this system and nevertheless the flood damages arise. Of course the same tax - payer have to pay for reconstruction of destroyed country. Pressure of the population living in flooded area resulted in spending more public money for developing the flood control system - similar situation in all of the countries exists. The world over experience leads to conclusion that a newly developed flood control system, especially structurally oriented system, will collapse in the case of the next big flood. Three typical explanations of above statement runs as follows:

1. Existing flood mitigation structures are inadequate for existing needs (to small numbers of reservoirs with sufficient capacity, inadequate parameters or lack of levees and another flood mitigation structures). It is typical opinion of hydraulic engineers provided to conclusion: we need much more money to develop the proper structures.

2. Our technical standards are inadequate; we have to change it i.e. by increasing the return period of designed floods. Many hydraulic engineers admit above opinion.

3. Structural measures are not a proper way for flood mitigation and in many cases they generate the increase of flood risk. It is typical opinion of ecologically oriented people.

I will try to show that all of the above opinions (and many others) are partially right.

But general conclusion looks as follows: flood control expenses belong to this category of public expenses which generate next, much greater public expenses - it is "viscious circle of the flood control". It is a point of view acceptable for most of the tax - payers who live (in Poland) mostly out of flood plain. Then we have to change existing, mostly structurally oriented flood control strategy. But we have to remember about the conflict of interest between majority of $\operatorname{tax}$ - payers and a group of tax - payers who live in the flood plane. Necessity of changing existing flood control strategy seems to be the next important experience resulted from the 1997 flood event, but satisfying solution can be achieved only taking into account the first experience i.e. necessity of compromise. Necessity of changing the strategy is rather commonly acceptable experience in Poland. However discussion about the new strategy seems to be very chaotic and full of misunderstanding. Necessity of ordering this discussion is the next important experience. I will try to formulate some proposal for ordering discussion about strategy of flood mitigation.

\section{IV $\square$ MITIGATION OF THE PARTICU- LAR, ABOVE IDENTIFIED FAULTS}

\section{- 4.1 Mitigation of the faults listed in 3.1.}

Again I stress that it is only my subjective experience and some of the listed faults are very controversial in Poland. (1). The possibility of preparation of QPF fully satisfying all hydrological applications is a myth. "Full satisfying" means without errors causing wrong decisions. Off course the fundamental task of the forecasts is to minimize the uncertainty about the future. But elimination of uncertainty seems to be impossible. Generally I agree with the statement formulated by Karl Popper that the world is practically unpredictable [3]. However it does not mean that the world is totally chaotic, but only that the total elimination of uncertainty is impossible. Then we have to eliminate uncertainty as far as possible but simultaneously we have to reveal residual uncertainty also as far as possible (it is a kind of formulation of the maximum entropy principle). The fundamental deficiency of the QPF (accessible in Poland) is their categorical formulation i.e. lack of probabilistic formulation of QPF. Some possibility of elimination of above deficiency is discussed in a paper by Parfiniewicz and Zelazinski [4]. It is a difficult problem to make a proper decision using probabilistic formulation of the QPF, but in paper by Malinowski and Zelazinski [5] it is shown that in the case of categorically formulated QPF proper decision concerning flood mitigation is impossible. Conclusion runs as follow: QPF for flood control should be presented in a form of probability distribu- 
tion or (most convenient for practical use) in a form of a "bunch" of future possible hietographs of precipitation. All of the new technology, especially mezo and local scale meteorological computer models are extremely useful for satisfaction of above needs.

(2). Creation of reliable information system for data collection and transmission using new high technology is only a technical (and of course monetary) problem. "Crystal System" developed in France in Loire basin seems to be a good example of above possibility. Information system oriented both to operational and non- operational flood control should contain set of simulation models, especially rainfall - runoff models, and hydrodynamic models (one and two-dimensional). Digital terrain model and geographical information systems should be used to visualize the result of simulation and to evaluate the flood damages. All of above tools were developed by a set of firms and the problem is only in selecting the best one for particular implementation. Some projects financed by a World Bank loan, oriented on flood mitigation started in 1998 in Poland. Important task of this project is to develop a new information system.

(3) Flood control managers should be intensively educated. First of all, they should admit that without uncertainty nobody needs to make any decisions! British economist Shackle [6] explains this point:

"In a predestinate world, decision would be illusory; in a world of perfect foreknowledge, empty; in the world without natural order, powerless. Our intuitive attitude to live implies non-illusory, non-empty, non-powerless decision ... Since decision in this sense excludes both perfect foresight and anarchy in nature, it must be defined as a choice in face of bounded uncertainty".

The following simple example can illustrate Shackle's statement. Chess is a decision game because gambler's knowledge about opponent moves is very imperfect. If we assume that the gambler knows everything about his opponent moves then it is clear that the gambler does not need to make any decisions. He must only make a set of moves, which guarantee a victory. Identification of this set can be difficult or time consuming but decision making is unnecessary. Fully certain situation is similar to situation of predestination. If predestination exists, then the absurd of decision making seems to be evident. Uncertainty and a risk of wrong decision resulted from uncertainty is an indispensable element of all decision making processes. Decision-makers should define goals and criterions, which allow evaluating given decisions, taking into account the uncertainty and risk. Those are tasks for decision makers.

Moreover the decision-makers should take into account that:

- The definition of goals and objective function under uncertainty is not a simple task. Flood losses are random with given (obviously only roughly known) probability distribution. During decision process we can change those distribution and nothing more. If we want to evaluate the results of our decision we have to evaluate not a unique number (i.e. expected losses) but the distribution of probability of flood losses (changed by our activity). Then each real decision problem (i.e. if we take uncertainty into consideration) becomes multi-criteria problem. Moreover we have to take into account both flood damages and additionally all of the social, economical and ecological impacts caused by given activity.
In the next paragraph I will try to formulate some proposals of goals and criterions adequate for floods mitigation purposes.

(4) Proper flood plains management is a legal problem. Flood plains (protected by embankments and unprotected) should be identified and classified depending on a risk of damages. For each category (zone) of risk adequate limitations of development should be defined by regulations. Without similar regulations breaking of viscious circle of flood control seems to be impossible.

(5) Flood frequency analysis can be used for designing hydraulic structures when destruction of structure is not a danger for human live and does not cause substantial social and economical damages. In other cases maximum probable flood method should be rather used. In paper by Zelazinski [7] some possibility of integration of flood frequency analysis and maximum probable flood method using bootstrap approach [9] is discussed. The idea of bootstrap approach to analyze rare event was first formulated by Klemes [9] and adopted to drought analysis by Zelazinski [10].

(6) Creation of a proper organization for operational flood control is a legal problem (in Poland). Operational flood control is similar to war and needs an organization similar to military. Some works performed in Poland after the 1997 flood seem to go in good direction. I think that professional organization similar to American Civil Guard should be commanded by the director of water authority during flood period.

(7) Population living in areas exposed to flood risk should be permanently educated using all possible media. Knowledge about proper behavior before and during the flood seems to be the most certain way to mitigation of human live losses. Personally I prefer decision games supported by a computer as a proper tool for education of managers. For education of flood plains residents the field exercises seem to be the best.

(8) Insurance policy should discourage users from improper management of the flood planes. It is a difficult legal problem because the increase of cost of insurance results in an decrease of value of property located on the flood planes. Attempt to change the existing insurance policy can cause protests using demagogy, look as follows: flood control is a duty of government therefore the owners of some properties located on flood planes do not have to pay for increase of risk.

(9) Our experiences gained during the big floods showed that for Polish mountain areas we need about 50 millions cubic meters of capacity of flood control reservoirs for each one thousand square kilometers of catchment. Full satisfaction of above needs is absolutely impossible. Valleys of Polish rivers are dense covered with buildings and first of all we do not have place for reservoirs. Total cost for creating so many reservoirs seems to be much greater than expected flood damages. Then we have to use new reservoirs only in these locations for which they are economically justified. Bad condition of existing levees is a fact. Experience showed in many cases, that levees were destroyed by infiltration of the water through and under the levees. The conclusion runs as follows: we have to construct drain systems for existing and new levees. Some simulations showed that in many cases the best way to reduce the risk is to increase the space between the levees instead of increasing their height. 


\section{$V$ - HOW TO CREATE A NEW FLOOD MITIGATION STRATEGY?}

\subsection{Definition}

Some definitions of the idea of strategy, are from game theory. They run as follows: strategy is a behavior of a participant of a game which permits to achieve a goal of game taking into account that there is an opponent who wants to achieve his goal. Flood mitigation belongs to the category "game with nature" and above definition seems to be adequate. We have to obtain an optimal strategy, which permits to achieve our goal minimizing the costs.

\subsection{Goals of flood control}

Everybody knows that floods cause the risk for human live and accepts that we have to save human live. Likewise everybody accepts that by flood mitigation measures we have to minimize economical, social and ecological damages induced by floods. Goals are listed in hierarchical, common accepted order. Above two simple goals (save of human live and damages reduction) are extremely difficult if we want to achieve them in practice. First of all in many cases above two goals are in contradiction. Embankments of the river valleys and developing other hydraulic structures cause false conviction about full safety situation. It can cause greater risk for human live. Moreover the amount of money which society can spend for flood control measures is always insufficient. If we spend more money to save human live then it will be a shortage of money for reducing economical damages and inversely. There are much more substantial contradictions among particular, possible goals. For instance all of the cities are interested in as fast as possible outflow of the flood waters out of their area. Of course it causes the increase of flood wave downstream of the city. Many structural flood control measures cause important impact on environment. Then we have to take into account the necessity of environmental protection. Generally by flood control measures we want to achieve:

- minimization of the risk for human live,

- minimization of the flood induced economical, social and environmental damages.

We want to achieve the above two goals (listed in hierarchical order) with as small as possible environmental impact. It is a typical multi-objective problem, with many contradictories inside, which should be solved under uncertainty.

\subsection{Criterions and procedures}

There are two substantial problems in formulating the adequate set of criterions:

- Evaluating the degree of satisfaction of each goal using identical units is impossible. Only for evaluating the economical damages and cost of flood control measures the monetary units can be used. Risk for human live, social and ecological damages can be evaluated only using subjective judgement. Then, so called utility function, indispensable for solution of the multi-criteria problem can be established using only negotiations among numerous participants.

- Because of deep uncertainty about future floods, future economical growth and needs, future technologies, environmental impacts and many other uncertainties we can eva- luate results of the given action also with major uncertainty. Many kinds of uncertainty cannot be described using probability theory (i.e. uncertainty of the future economical growth). Then we cannot use expected value of some variable as a criterion.

Taking into account the above troubles, formulation of the objective function in a form of the mathematical expression is rather impossible. The approach commonly used in Environmental Impact Assessment (EIA) and developed in the USA for the selection of the best route of a highway seems to be more practical. The set of possible alternatives of route is evaluated by experts and public during a long iterative process, which eliminates disadvantageous alternatives and permits to select the best one. Of course each of the participants of discussion uses his subjective criteria. But before discussion all participants should perform an agreement about the form of expression of their opinion. For instance, "number 10 marked a very good solution, number 1 solution without advantages". A team of experts and public representatives evaluate each alternative taking into account many different possible benefits and impacts (cost, destruction of the environment, risk of accidents, social and economical growth, uncertainty involved into the process and many others). The good tool for performing and ordering discussion is Leopold's matrix in the form of printed tables or computer programs.

I suggest the procedure for preparation of the optimal strategy, which contains the following steps in order:

1. Identification and call of the team for preparation of the optimal strategy of flood control. This team should contain many participants for proper representation of the different knowledge and different groups of interest (hydraulic engineers, hydrologists, environmentalists, public participants, economists, politicians and many, many others).

2. Preparation of the list of general principles for the future joint works. All of the participants should accept those principles. The following list of principles seems to be adequate: (a) strategy should be submitted under principles of sustainable development; (b) there are two hierarchical goals of flood control in order - save of human live and minimization of economical and ecological flood damages; (c) cost of measures for saving the human live should be as low as possible (assuming practical elimination of risk) and cost of measures for minimization of flood damages should be considerably lower than expected flood losses; (d) succession of mitigation measures (ordered schedule of investments) depends on efficiency; (e) in all of these cases, when a given activity can cause different unpredictable results (in consequence of uncertainty) we have to consider the worst possible scenario and we have to apply Hypocrites' principle; (f) strategy should be oriented on breaking the viscious circle of flood control.

3. The generation of the set of partial possible strategies for flood mitigation. Partial strategy uses only one specific action. For as complex a problem as flood control an optimal strategy must be complex. It means that the optimal strategy should contain given combination of the partial strategies. The following list of partial strategies seems to be adequate: (a) information, organization and evacuation strategy; (b) structural strategy (levees, reservoirs, lateral canals polders) oriented both on constructing new structures and upgrading existing one; (c) flood plain management strategy; 
(d) proper insurance policy; (e) education and training of managers and residents of flood plains; (f) research works oriented on coping with floods.

4. Preparation of the set of computer models and data bases. Computer simulation seems to be the only way for universal research of particular partial and complex strategies (this task can be prepared simultaneously with above listed).

5. Preparation of the first list of the complex strategies using for example "storm of brains" approach. Particular complex strategies should have different parts of individual partial strategies depending on the opinion of their authors. 6. Successive evaluation, correction and elimination of the particular strategies using proper databases and simulation models (during discussion among all participants of the process). Correction should be performed by changing participation of partial strategies in a given complex strategy. This approach gives a possibility for rational and ordered discussion and for justification of all opinions expressed by participants of discussion. Probably as the result of a described process we can obtain few acceptable complex strategies and final choice will be a task for politicians.

Described approach seems to be realistic, but we have to eliminate "trap of the wishful thinking". It is a serious danger as an experience gained before and after the 1997 flood shows. All of the flood control programs prepared during last 50 years in Poland has never been finished because of the shortage of money. Those structurally oriented programs, were prepared by hydraulic engineers and absolutely ignored economical possibilities of the country. From a very long list of levees and reservoirs only a few were established. Some reservoirs were constructed $20-30$ years without of course any effects - real benefits can come after the end. Moreover in situation of major differences between expectations and possibilities only a force of groups interested in a given investment decided about the allocation of money, then very often the benefit was an illusory. Then the very important experience runs: strategy or program should take into account realistic evaluation of the amount of the money which government can spend for flood mitigation.

\section{VI - FINAL REMARKS}

Most of the conclusions formulated in this paper were known before the 1997 flood. It was a result of the analysis of big flood events during last years (Mississippi 1993, Rain 1993 and 1995). Those conclusions were published and presented on technical conferences [11] and caused objections of conservatively oriented hydraulic engineers. 1997 flood event showed who is right. But unfortunately many actions performed after the flood showed that dangerous "viscious circle of flood control" and "trap of wishful thinking" are continually topical.

\section{References}

[1] Miedzynarodowa Komisja Ochrony Odry Przed Zanieczyszczeniem. (1999): Powdry w dorzeczu Odry w 1997 r.

[2] KAPUR, J. N. (1983): Twenty five years of maximum entropy principle J. Math. Phys. Sciences 17. No. 2, pp. $103-156$

[3] POPPER, K., R., (1982): The Open Universe: An Argument for Indeterminism. Postscript to the Logic Scientific Discovery.

[4] Parfiniewicz J., Zelazinski J. (1991): The uncertainty model in flood control system: the generator of floods scenarios by applying QPF stochastic/expert approach. First Symposium on the applications of meteorology and their economic benefits, 24-26 April, Besancon, France, p. 324-342.

[5] MALINOWSKI K., ZELAZINSKI J. (1990): Reservoir Systems: Operational Flood Control. (SYSTEMS \& CONTROL ENCYKLOPEDIA supplementary volume 1) Pergamon Press.

[6] Shackl.e G. L. S., (1961): Decision, Order, and Time in Human Affairs. Cambridge University Press, Cambridge.

[7] ZEL.AZINSKI J., (1998 a): Uncertainty in water management. Geographia Polonia 71, 1998

[8] EFron, B., TibShiRani, R., (1993): An Introduction to the Bootstrap. Chapman \$ Hall

[9] KLemes, V., (1993): Probability of extrema hydrometeorological events - a different approach. Proceedings of the Yokohamas Symposium, July 1993.

[10] Zelazinski J. i in., (1998b): Metody wspomagania optymalnych strategii ograniczajacych skutki suszy. IMGW Matrialy Badawcze, Seria: Hydrologia i Oceanologia - 24

[11] BoBINSKI E., ZelAZINSKI J., (1997): Mity i zludzenia ochrony przeciwpowodziowej - skutki i metody przezwyciezenia (Myths and illusions of flood protection - results and methods of overcome). Zagrozenia powodziowe w zlewniach gflood protection - resultowo - Techniczna, Bielsko - Biala 14 - 16 kwietnia 1997. 